\title{
LTC Vacuum Blasting Machine (Concrete): Baseline Report: Greenbook (Chapter)
}

$\begin{array}{cc} & \text { RECEIVED } \\ & \text { MAR } 181998 \\ \text { Topical Report } & \text { O S T I } \\ \text { July 31, 1997 } & \end{array}$

Work Performed Under Contract No.: DE-FC21-95MC32260

For

U.S. Department of Energy

Office of Environmental Management

Office of Technology Development 1000 Independence Avenue

Washington, DC 20585
U.S. Department of Energy

Office of Fossil Energy

Federal Energy Technology Center Morgantown Site

P.O. Box 880

Morgantown, West Virginia 26507-0880

DISTRBUTION OF THIS DOCUMENT IS UNLLMTEE
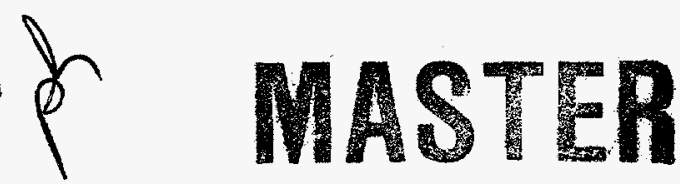

By

Operating Engineers National Hazmat Program

250 Airport Circle

Beaver, West Virginia 25813 


\section{Disclaimer}

This report was prepared as an account of work sponsored by an agency of the United States Government. Neither the United States Government nor any agency thereof, nor any of their employees, makes any warranty, express or implied, or assumes any legal liability or responsibility for the accuracy, completeness, or usefulness of any information, apparatus, product, or process disclosed, or represents that its use would not infringe privately owned rights. Reference herein to any specific commercial product, process, or service by trade name, trademark, manufacturer, or otherwise does not necessarily constitute or imply its endorsement, recommendation, or favoring by the United States Government or any agency thereof. The views and opinions of authors expressed herein do not necessarily state or reflect those of the United States Government or any agency thereof. 


\section{DISCLAIMER}

Portions of this document may be illegible electronic image products. Images are produced from the best available original document. 


\section{LTC VACUUM BLASTING MACHINE (CONCRETE)}

\section{GREEN BOOK}

\section{TABLE OF CONTENTS}

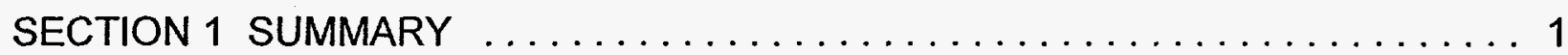

TECHNOLOGY DESCRIPTION $\ldots \ldots \ldots \ldots \ldots \ldots \ldots \ldots \ldots \ldots \ldots$

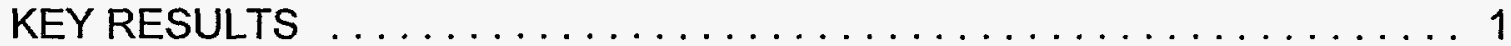

SECTION 2 -TECHNOLOGY DESCRIPTION $\ldots \ldots \ldots \ldots \ldots \ldots \ldots \ldots \ldots \ldots$

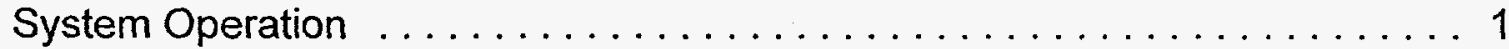

SECTION 3 - HEALTH AND SAFETY EVALUATION $\ldots \ldots \ldots \ldots \ldots \ldots \ldots \ldots$

General Health and Safety Concerns $\ldots \ldots \ldots \ldots \ldots \ldots \ldots \ldots \ldots .2$

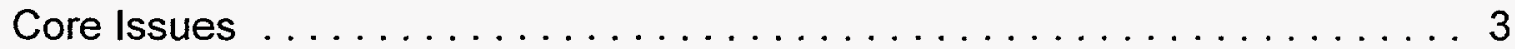

Best Management Practices $\ldots \ldots \ldots \ldots \ldots \ldots \ldots \ldots \ldots \ldots \ldots \ldots$

Industrial Hygiene Monitoring $\ldots \ldots \ldots \ldots \ldots \ldots \ldots \ldots \ldots, \ldots$

Human Factors Interface $\ldots \ldots \ldots \ldots \ldots \ldots \ldots \ldots \ldots \ldots \ldots, 6$

Emergency Response/Preparedness $\ldots \ldots \ldots \ldots \ldots \ldots \ldots \ldots \ldots 6$

SECTION 4 - TECHNOLOGY APPLICABILITY $\ldots \ldots \ldots \ldots \ldots \ldots \ldots \ldots \ldots$

SECTION 5 - REGULATORYIPOLICY ISSUES $\ldots \ldots \ldots \ldots \ldots \ldots \ldots \ldots \ldots$

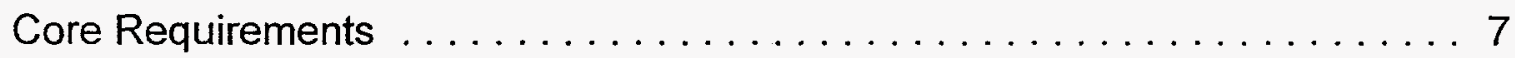

Special requirements $\ldots \ldots \ldots \ldots \ldots \ldots \ldots \ldots \ldots \ldots \ldots \ldots, \ldots$

Best Management Requirements $\ldots \ldots \ldots \ldots \ldots \ldots \ldots \ldots \ldots \ldots$

Core Training Requirements $\ldots \ldots \ldots \ldots \ldots \ldots \ldots \ldots \ldots \ldots, 9$

Technology-specific Training $\ldots \ldots \ldots \ldots \ldots \ldots \ldots \ldots \ldots \ldots \ldots \ldots, \ldots \ldots \ldots, \ldots \ldots$

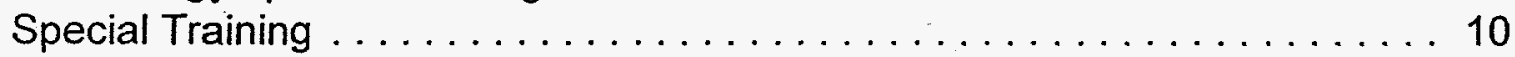

Best Management Practices $\ldots \ldots \ldots \ldots \ldots \ldots \ldots \ldots \ldots \ldots \ldots . \ldots \ldots \ldots$

SECTION 6 - OPERATIONAL CONSIDERATIONS AND

RECOMMENDATIONS ............................ 10

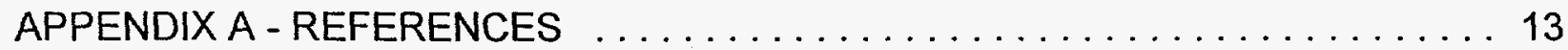

APPENDIX B - INDUSTRIAL HYGIENE DATA .................... 14 


\section{LTC VACUUM BLASTING \\ HUMAN FACTORS EVALUATION}

\section{PART 1 - SUMMARY}

\section{TECHNOLOGY DESCRIPTION}

The LTC shot blast technology was tested and is being evaluated at Florida International University (FIU) as a baseline technology. In conjunction with FIU's evaluation of efficiency and cost, this report covers the evaluation conducted for safety and health issues. It is a commercially available technology and has been used for various projects at locations throughout the country.

The LTC 1073 Vacuum Blasting Machine uses a high-capacity, direct-pressure blasting system which incorporates a continuous feed for the blast media. The blast media cleans the surface within the contained brush area of the blast. It incorporates a vacuum system which removes dust and debris from the surface as it is blasted.

\section{KEY RESULTS}

The safety and health evaluation during the testing demonstration focused on two main areas of exposure: dust and noise. Dust exposure during maintenance activities was minimal, but due to mechanical difficulties dust monitoring could not be conducted during operation. Noise exposure was significant. Further testing for each of these exposures is recommended because of the outdoor environment where the testing demonstration took place. This may cause the results to be inaccurate. It is feasible that the dust and noise levels will be higher in an enclosed environment. In addition, other safety and health issues found were ergonomics, heat stress, tripping hazards, electrical hazards, lockout/tagout, and arm-hand vibration.

\section{PART 2 \\ TECHNOLOGY DESCRIPTION}

\section{SYSTEM OPERATION}

In conjunction with Florida International University's evaluation of efficiency and cost, this report covers the evaluation conducted for safety and health issues. 
During the blasting operation, the blast nozzle of the LTC 1073 Vacuum Blasting Machine propels the abrasive shot at high speed against the surface to be cleaned. After cleaning the surface, the abrasive shot, together with the rust or coating that was removed from the surface, is vacuumed back into the machine through the suction hose. The dust separator contains angled steel collision pads which, working with the force of gravity, allow any reusable abrasive to fall back into the pressure vessel. The abrasive and dust pas though a fine wire mesh screen that is under the last collision pad. Particles too large to pass through the screen are caught by a sieve. Dust is drawn from the dust separator into the filter chamber, the remainder is drawn into the filter. The filters are manually back-flushed to prevent clogging. After back-flushing to prevent clogging, dust is dumped from the dust chamber into the dust collection bag or drum by operation of the bellows valve.

The abrasive for blasting is cycled through a dual chamber pressure vessel. When the trigger on the blast head is activated, the abrasive control valve is opened and the abrasive, is forced under pressure into the blast hose. This pressurized air, combined with air from the blast air assist line, propels the abrasive through the blast hose to the blast nozzle.

\section{PART 3 \\ HEALTH AND SAFETY EVALUATION}

\section{GENERAL SAFETY AND HEALTH CONCERNS}

Personnel where the vacuum blasting machine technology is being used need to be concerned with two categories of safety and health issues. Core issues are those that are based on current safety and health regulatory requirements. Best management practices are related to issues that are not based on current safety and health regulations but are key elements in preventing worker injury and illness on the job.

Safety and health issues of concern with the vacuum blasting machine technology included:

\section{Core Issues:}

- Tripping hazards - the air lines and vacuum hoses needed to operate the equipment are tripping hazards. The need for stringent housekeeping must be evaluated.

- Pinch points - the potential exists for the operator to have his/her fingers/hand injured during operation if the hand is placed in the area of the shot head or near any moving parts of the equipment. Blasting mode should never be activated while maintenance is being conducted on the head. This will be considered under a lockout/tagout program. 
- Lockout/Tagout - the user of the technology will need to develop a lockout/tagout program to assure there is not an accidental release of energy during maintenance/repair activities.

- Noise - the user was subjected to a significant amount of noise while operating the vacuum blasting machine used during the testing demonstration.

- Dust - the equipment generated some visible dust during operation, and larger debris and shot were left on the surface being blasted. The dust generated was not observed in the breathing zone of the operator. The amount of dust generated in the breathing zone of the operator may change based on the environment in which the concrete decontamination is taking place. Therefore, the user of the technology will need to develop a sampling plan based on the individual site needs.

Shot and dust were left on the surface during the blasting operations. This has the potential to become an airborne hazard. In addition, the shot left on the surface caused the surface to become very slippery.

\section{Best management practices:}

- Heat stress - the operator was subjected to an increase in heat stress due to the need to utilize Anti-C PPE. The user will need to develop a heat stress program for the environment in which the technology is being used, taking into consideration any PPE that may need to be utilized.

Ergonomics - the user was subjected to some ergonomic stressors that need to be taken into consideration, such as stooping, bending, twisting, kneeling, and lifting. Of particular concern is the manual manipulation of the shot head. This adds stress to the back, and causes an increase in exposure to the contaminant. The frames the shot heads were mounted on were difficult to steer (manual steering) and caused the operator to assume awkward positions.

- Struck by hazards - the grit being used as the shot was sprayed upward and outward after striking the surface. It could be a severe eye injury hazard. The operator needs to utilize goggles and a face shield instead of safety glasses.

Communication - due to the noise generated by the technology during operation, communication can be difficult. Personnel working in the area should be familiar with and use hand signals when needed. 


\section{Industrial Hygiene Monitoring}

During the current testing demonstration with the LTC vacuum blasting machine, sampling was conducted for dust and noise. In addition, the wet-bulb globe temperature was monitored to evaluate heat stress. Observational evaluation was conducted for ergonomics and arm-hand vibration.

Through general observational techniques the potential for ergonomic problems was evaluated during the testing demonstration. There is potential for muscle/back stress and/or injuries due to bending, twisting, and lifting associated with setup, operation, maintenance, and decontamination. Of particular concern is the potential for back injury due to the manual operation of the blasting head. The heads mounted on manually operated carts were difficult to maneuver, but did eliminate the bending and lifting associated with manual operation.

Heat stress was monitored using a QuestTemp ${ }^{\circ} 15$ Heat Stress Monitor. The wet-bulb globe temperature was used to determine the work/rest regimen in accordance with the American Conference of Governmental Industrial Hygienist (ACGIH) recommendations. The wet-bulb globe temperature was adjusted for the type of clothing, including PPE, that the worker was wearing.

In addition, the worker's blood pressure, pulse, and temperature were monitored throughout the day. No problems were encountered due to heat stress, but the worker's comfort level was decreased when wearing the Anti-C PPE. While heat stress will be increased while wearing PPE, the overall heat stress response will vary from worker to worker. Each situation in which the current technology is used will need to be evaluated for the heat stress potential, taking into consideration the wet-bulb globe temperature, PPE in use, physical condition of the worker, and worker acclimatization.

Dust monitoring was conducted with a sampling train consisting of an SKC IOM Inhalable dust sampler coupled with an MSA Escort Elf air sampling pump. Pre- and post-sampling calibration was accomplished using a BIOS International DryCal DC1 primary calibration system. Sampling filters were desiccated pre- and post-sampling and weighed on a Denver instrument Company a-200DS scale. Sampling was conducted in accordance with NIOSH method 0500.

Personal dust sampling was conducted on the equipment operators during maintenance operations. Personal dust sampling results of $0.0 \mathrm{mg} / \mathrm{m}^{3}$ and 45.4545 $\mathrm{mg} / \mathrm{m}^{3}$ were obtained for the operators. The second value exceeds the Occupational Safety and Health Administration (OSHA) permissible exposure limit (PEL) and the ACGIH threshold limit value (TLV) of $15 \mathrm{mg} / \mathrm{m}^{3}$ and $10 \mathrm{mg} / \mathrm{m}^{3}$ respectively for total dust. One operator was standing at ground level, while a second operator worked on the machine above him. A large amount of debris appeared to have fallen on the sampling filter, and a high dust reading was registered. There was a notable amount of shot left 
on the blasted surface. This could potentially become an airborne inhalation hazard. Dust sampling was not conducted during operations due to mechanical problems with the blasting equipment. It is recommended that sampling be conducted while the shot blasting operation is being conducted in a closed environment. A complete air sampling plan for a site would need to be developed to include not only dust but other contaminants specific to the concrete decontamination project. (See Appendix B for sampling data).

Personal noise monitoring was conducted using Metrosonic $\mathrm{db}-3100$ data logging noise dosimeters. Calibration was conducted pre- and post-monitoring using a Metrosonic CL304 acoustical calibrator. Monitoring was conducted on Operator Number 1 for 3.4 hours (205 minutes) during operation of the centrifugal shot blast system. Monitoring during this time showed a noise dose of $354.16 \%$, which gives an 8-hour time-weighted average (TWA) of $99.1 \mathrm{dBA}$. If the operator continued to have the same level of noise exposure during the 8-hour shift, a projected 8-hour TWA would produce a noise dose of $827.72 \%$, or an 8-hour TWA of $105.2 \mathrm{dBA}$. Monitoring conducted on Operator Number 2 for 3.4 hours (204 minutes) showed a noise dose of $337.6 \%$, which gives an 8-hour TWA of $98.7 \mathrm{dBA}$. If the operator continued to have the same level of noise exposure during the 8-hour shift, a projected 8-hour TWA would produce a noise dose of $794.56 \%$ or an 8 -hour TWA of $104.9 \mathrm{dBA}$.

The OSHA allowable PEL for noise is a $100 \%$ dose or an 8 -hour TWA of $90 \mathrm{dBA}$. The above noise doses and TWA's show a potential for overexposure depending on the amount of time spent operating the equipment. Both operators were overexposed after 3.4 hours of operation. At these exposure levels, personnel would be required to be included in a hearing conservation program. Feasible engineering controls, administrative controls, and personal protective equipment (hearing protection devices) need to be used as appropriate. The percentage of time spent at each loudness level that comprises the exposures can be seen in Appendix B.

During the 3.4 hours of operation for Operator Number 1, the noise levels were averaged for each one minute period of time and then an overall average was calculated and gave an average exposure level of $104.9 \mathrm{dBA}$ for an $80 \mathrm{~dB}$ cutoff level and $104.8 \mathrm{dBA}$ for a $90 \mathrm{~dB}$ cutoff level. The average exposure level for Operator Number 2 was $105.2 \mathrm{dBA}$ for an $80 \mathrm{db}$ cutoff level and 105.1 dBA for a $90 \mathrm{db}$ cutoff level for the 3.4 hours of operation. OSHA requires an $80 \mathrm{db}$ cutoff for hearing conservation measurements and a $90 \mathrm{db}$ cutoff for engineering controls compliance measurements. The maximum sound level observed during the measurement period was $119.0 \mathrm{dBA}$ for Operator Number 1 and $119.2 \mathrm{dBA}$ for Operator Number 2. The highest instantaneous sound pressure level was $140.5 \mathrm{~dB}$ for Operator Number 1 and $136.7 \mathrm{~dB}$ and $138.9 \mathrm{~dB}$ for Operator Number 2.

These measurements define noise as an exposure problem for personnel operating the LTC vacuum blasting machine. It must also be noted that the equipment was being operated in an open outdoor environment at the time of the measurements. Operation 
in an enclosed facility would have the potential to increase the noise level due to other influences such as vibration and reverberation. Therefore, it is recommended that noise monitoring be conducted while the equipment is being operated in a closed environment.

\section{HUMAN FACTORS INTERFACE}

The technologies being tested for concrete decontamination and decommissioning are targeted for alpha contaminated concrete, therefore, the equipment operator and assistant were dressed out in Anti-C (alpha radiation) PPE which included cloth suit, hood, inner and outer boots, inner and outer gloves, and full face air-purifying respirator. Due to the full-face respirator, operators had some visibility problems while operating the equipment and performing maintenance when wearing Anti-C PPE. There was also a decrease in dexterity due to the gloves, which caused a loss of tactile sensation. In addition, the need to perform work in the Anti-C PPE caused some increase in heat stress for the operator and assistant.

If the concrete being decontaminated had contamination other than or in addition to alpha radiation, additional levels of protection, such as Level A or Level B PPE, may be required for the operator. These may create additional human interface problems such as a greater decrease in visibility and manual dexterity, an increase in heat stress, and an overall increase in physical stress. It is recommended that additional safety and health evaluations be conducted utilizing these higher levels of protection.

The main ergonomic concern was manually operating the blasting head. This greatly increased the potential for exposure to the dust and associated contaminants and there was extreme potential for back injury.

\section{EMERGENCY RESPONSE/PREPAREDNESS}

The use of the LTC Americas Vacuum Blasting Machine would not be applicable to emergency response.

Emergency response/preparedness must be part of every hazardous waste site safety and health plan. In addition to credible site emergencies, site personnel must plan for credible emergencies in connection with the vacuum blasting machine.

All precautions used when responding to an emergency situation at the site will apply. Before entering an area where the vacuum blasting machine is being used, the equipment needs to be completely shut down (de-energized).

This technology does not appear to present any conditions that would lead to out-ofthe-ordinary emergencies. 


\section{PART 4 \\ TECHNOLOGY APPLICABILITY}

On observation the technology did not deposit much visible dust into the atmosphere and air monitoring did not show a significant dust level. This was difficult to assess due to the windy outdoor testing environment. There was a large amount of shot left on the surface during blasting operation. The system needs to be evaluated to determine if an increase in vacuum air flow would help with this problem.

The vacuum blasting machine will need to be torn down to be decontaminated. This will not necessarily guarantee that decontamination for alpha will be complete and it will be difficult to survey for alpha contamination due to all of the small spaces inherent in the equipment which are hard to reach with a probe. There is also concern for the amount of contamination that may have been spread to the internal parts of the equipment when shot that has been on the surface is deposited back into the shot blaster for use. If total decontamination is not possible, the equipment may need to be considered a consumable.

\section{PART 5 \\ REGULATORYIPOLICY ISSUES}

The site safety and health personnel where the LTC shot blasting technology is being used need to be concerned with safety and health regulations applicable to the issues discussed above. Regulations that apply may be divided into four categories. Core requirements are those regulations that would apply to any hazardous waste work site, regardless of the type of job. Technology specific requirements are those regulations that apply due to the specific technology being used. Special requirements are standards and policies that are specific to the technology itself but are required by reference in a regulation. Best management practices are not required but are recommended by organizations such as the American National Standards Institute (ANSI), the National Institute of Occupational Health and Safety (NIOSH), Department of Energy (DOE), National Fire Protection Association (NFPA), etc. These regulations/standards may include but not be limited to the following:

\section{Core requirements:}

- OSHA 29 CFR 1926.25 Housekeeping

- OSHA 29 CFR 1910.141 Sanitation (1910.141(a)(3) covers housekeeping)

- OSHA 29 CFR 1926.53 lonizing Radiation 
- OSHA 29 CFR 1910.96 lonizing Radiation

- OSHA 29 CFR 1926 Subpart Z Toxic and Hazardous Substances

- OSHA 29 CFR 1910 Subpart Z Toxic and Hazardous Substances

- OSHA 29 CFR 1926.59 Hazard Communication

- OSHA 29 CFR 1910.1200 Hazard Communication

- OSHA 29 CFR 1926.64 Process Safety Management of Highly Hazardous Chemicals

- OSHA 29 CFR 1910.119 Process Safety Management of Highly Hazardous Chemicals

- OSHA 29 CFR 1926.65 Hazardous Waste Operations and Emergency Response

- OSHA 29 CFR 1910.120 Hazardous Waste Operations and Emergency Response

- Occupational Safety and Health Act 1970(5)(a)(1) General Duty Clause

Technology Specific Requirements:

- OSHA 29 CFR 1910 Subpart O Machinery and Machine Guarding

- OSHA 29 CFR 1910.147 The Control of Hazardous Energy (Lockout/Tagout)

- OSHA 29 CFR 1926.52 Occupational Noise Exposure

- OSHA 29 CFR 1910.95 Occupational Noise Exposure

- OSHA 29 CFR 1926.103 Respiratory Protection

- OSHA 29 CFR 1910.134 Respiratory Protection

- OSHA 29 CFR 1926.102 Eye and Face Protection

- OSHA 29 CFR 1910.133 Eye and Face Protection

- OSHA 29 CFR 1926.28 Personal Protective Equipment 
OSHA 29 CFR 1910.132 General Requirements (Personal Protective Equipment)

OSHA 29 CFR 1926.23 First Aid and Medical Attention

OSHA 29 CFR 1910.151 Medical Services and First Aid

- ACGIH Threshold Limit Values for Chemical Substances and Physical Agents and Biological Exposure Indices

In addition to the above regulations and policies, it is imperative that all workers have appropriate and adequate training for the task and associated safety and health conditions. Training that would be required may be divided into four categories. Core training is that which is required for anyone entering a hazardous waste site to perform work, regardless of the type of job. Technology specific training is that training that is specific to the technology and required by safety and health standards. Special training is that which is specific to the technology to assure the worker is adequately trained for the task but is not necessarily required by safety and health standards. Best management practices are trainings that while not mandated by health and safety standards, provide information and knowledge to the worker that will allow the worker to perform his/her job safely. Training to be applied for the heavy duty roto peen may include but not be limited to:

Core Training Requirements:

- HAZWOPER (Hazardous Waste Operations and Emergency Response)

- HAZCOM (Hazard Communication)

- Radiation Safety (Radiation Worker Training) for radiation sites

Technology Specific Training:

- Respiratory Protection

- Hearing Conservation

- Personal Protective Equipment

- Lockout/Tagout 
Special training:

- Job specific training for equipment operation

\section{Best Management Practice training:}

Ergonomics (proper lifting, bending, stooping, kneeling, safe shoveling techniques)

- Heat stress (learning to recognize signs and symptoms)

- CPR/First Aid/Emergency Response/Blood-borne Pathogens

- Hand Signal Communication

- Construction Safety (OSHA 500) and or General Industry Safety (OSHA 501)

\section{PART 6 \\ OPERATIONAL CONSIDERATIONS \& RECOMMENDATIONS}

Recommendations made here for improved worker safety and health take into consideration the operation of the centrifugal shot blast without a HEPA vacuum system. Specific recommendations include:

Workers must be aware of the tripping hazards associated with hoses and cords that are necessary to operate the equipment. Keeping these as orderly as possible in compliance with good housekeeping regulations will help avoid injury due to tripping. In addition, the operators had to find somewhere to place tools that were being used during operations. A specific place for tools located on the operating station would improve housekeeping in this area.

- Operators and assistants need to have training in ergonomics to assure proper techniques in lifting, bending, stooping, twisting, etc. during equipment setup and operation. The manual operation of the blasting head caused the most ergonomic concern. The carts used for the other heads were difficult to steer. The carts and heads should be evaluated for easier control, needing to apply less force to move, and elimination of manual head operation.

- During blasting operations, there was a significant amount of shot left on the surface. This was collected by running the blast head over the area like a vacuum cleaner. In addition, shot that is not left on the surface is recycled back into the equipment for reuse. Both of these practices have the potential to 
spread contamination to the internal parts of the equipment. The vacuum system needs to be evaluated to determine if an increase in air flow will help this problem.

The shot left on the surface made it very slippery. A design change to the vacuum system may also help with this problem. The shot left on the surface can create a secondary waste problem because when it gets wet it rusts.

- There is overexposure to noise during operation of the technology. Since testing was done in an outdoor environment, it is plausible that the noise levels would increase in an enclosed environment. The equipment needs to be evaluated for possible engineering controls to help decrease the noise exposure to the operator. If engineering controls are not possible, administrative controls, and/or adequate hearing protection must be incorporated during operation.

During operation of the vacuum blasting machine, grit became a potential projectile. This could lead to a severe eye injury. The operator needs to use goggles and a face shield instead of safety glasses.

The "dust dump" and "filter clean" controls on the vacuum blasting machine look the same except for small printed labels ("vacuum pressure" and "blast pressure"). This could lead to operator error. The controls need to be evaluated for human factors engineering design. The controls could be made to look different from each other, labeling could be larger, color coding could be used to provide redundancy, etc.

- There was a substantial amount of grit lying on top of the vacuum blasting machine. This has the potential to spread contamination to the worker and to other areas of the environment. Good housekeeping procedures need to be applied.

Several times the operator conducted a filter cleaning operation with the top of the unit open. A large amount of the dust was created by this action. This caused an exposure to the contaminant for the operator. Standard Operating Procedures (SOPs) should never allow filter cleaning to be conducted with the top of the unit open. An interlock system that does not allow filter cleaning to be conducted while the top is open would alleviate this problem.

- When the grit was being dumped into the vacuum blasting machine, there was a cloud of visible dust. This creates an airborne exposure to the worker.

Respiratory protection may need to be used during grit loading.

During maintenance operations, while wearing Anti-C PPE, the operator had some dexterity problems with the small nuts and bolts. The use of larger wing nut type bolts would help with this problem. 
- The only way the operator can tell if the drum is full is by manually checking. An automatic warning system would reduce the likelihood of the drum overfilling, increasing its weight, and so creating more potential for back stress/injury during change out.

Due to the windy outdoor environment in which the testing demonstration was conducted and therefore, the dust and noise monitoring was conducted, it is recommended that further testing for dust exposure and noise exposure be conducted while the technology is used in an enclosed environment similar to environments in which it would be used at a hazardous waste clean-up site. This would also allow for a more thorough evaluation of the heat stress to be encountered while wearing the appropriate PPE.

It is also recommended that the operation and maintenance activities be evaluated while the operator is wearing Level A and Level B PPE, since these levels may be needed in environments where the concrete contamination is mixed in nature or other than radiation.

The safety and health issues discussed throughout this report could be reduced, and in some cases eliminated, if this type of scabbling technology could operate remotely. 


\section{APPENDIX A \\ REFERENCES}

Occupational Safety and Health Standards for General Industry, 29 CFR Part 1910, Occupational Safety and Health Administration United States Department of Labor, 1995

Occupational Safety and Health Standards for the Construction Industry, 29 CFR Part 1926, Occupational Safety and Health Administration United States Department of Labor, 1995

Threshold Limit Values(TLV's) for Chemical Substances and Physical Agents and Biological Exposure Indices (BEl's), American Conference of Governmental Industrial Hygienists, 1995-1996

ANSI 1986, Guide for the measurement and evaluation of human exposure to vibration transmitted to the hand, New York, NY: American National Standards Institute, ANSI S3.34 
APPENDIX B

IH SAMPLING DATA

\begin{tabular}{|c|c|c|c|}
\hline \multicolumn{4}{|c|}{$\begin{array}{l}\text { Concrete Cleaning, lnc. Centrifugal Shot Blast } \\
\text { Total Dust Sampling }\end{array}$} \\
\hline \%xil: & 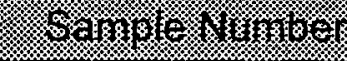 & 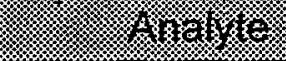 & reser. \\
\hline $6 / 11 / 96$ & 061196-FIU-025 & Blank & $0.0000 \mathrm{mg} / \mathrm{m}^{3}$ \\
\hline $6 / 11 / 96$ & 061196-FIU-026 & Total dust & $0.0000 \mathrm{mg} / \mathrm{m}^{3}$ \\
\hline $6 / 11 / 96$ & 061196-FIU-027 & Total dust & $45.4545 \mathrm{mg} / \mathrm{m}$ \\
\hline
\end{tabular}

* The OSHA PEL for total dust is $15 \mathrm{mg} / \mathrm{m}^{3}$ and the ACGIH TLV is $10 \mathrm{mg} / \mathrm{m} 3$. Current sampling was conducted for total dust. The need to sample for respirable dust and silica has to be considered during concrete decontamination and decommissioning activities. 


\section{NOISE SAMPLING}

Amplitude Distribution Data

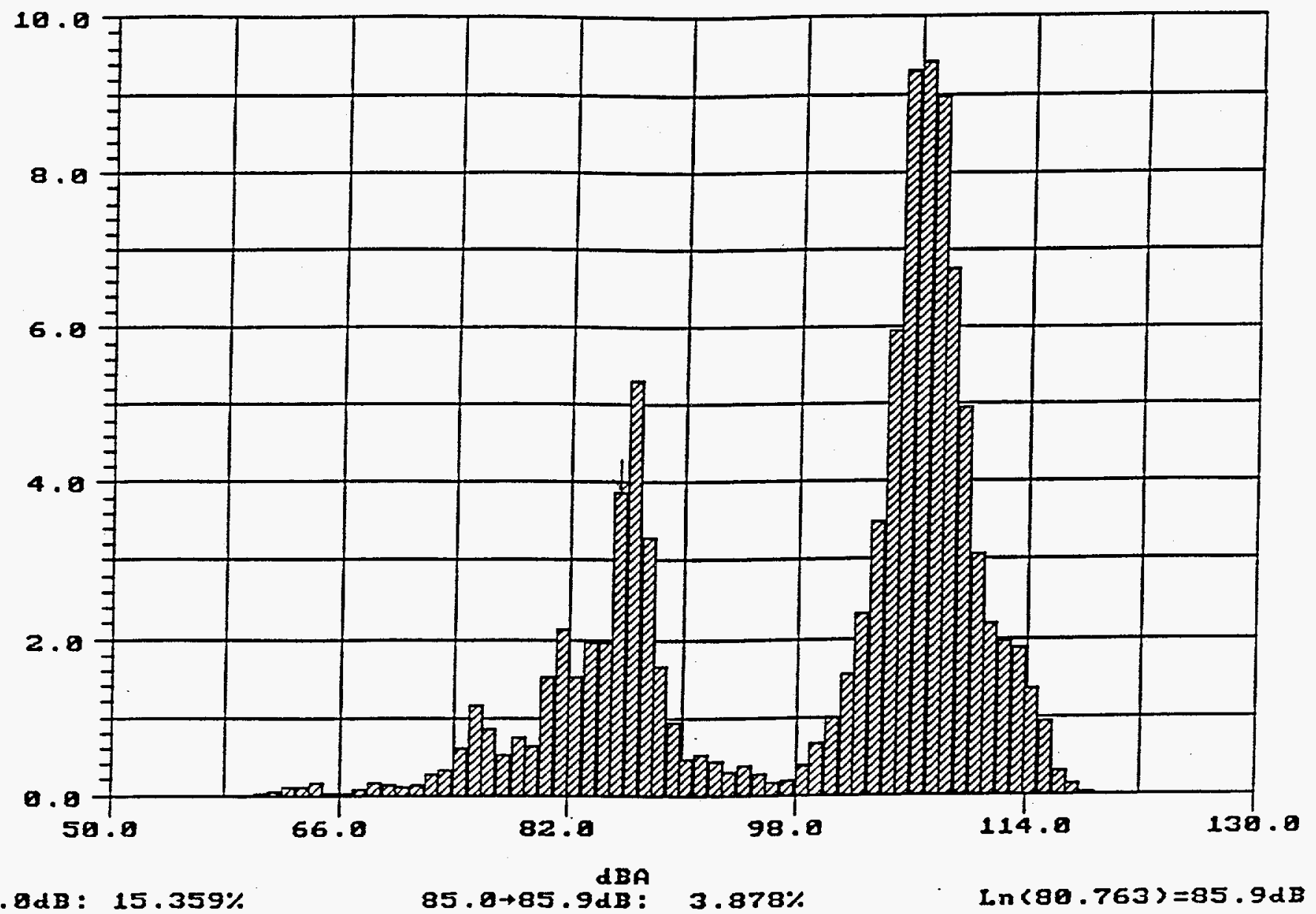

The percentage of time spent at each decibel level can be obtained from the graph. As shown, $15.359 \%$ of the time the noise exposure was less than $85 \mathrm{dBA}$ which means that the majority of the time or $84.641 \%$ of the time the noise exposure was at sound levels above $85 \mathrm{dBA}$. OSHA requires that a hearing conservation program be initiated if the 8-hour TWA is $85 \mathrm{dBA}$. 
Anplitude Distribution pata

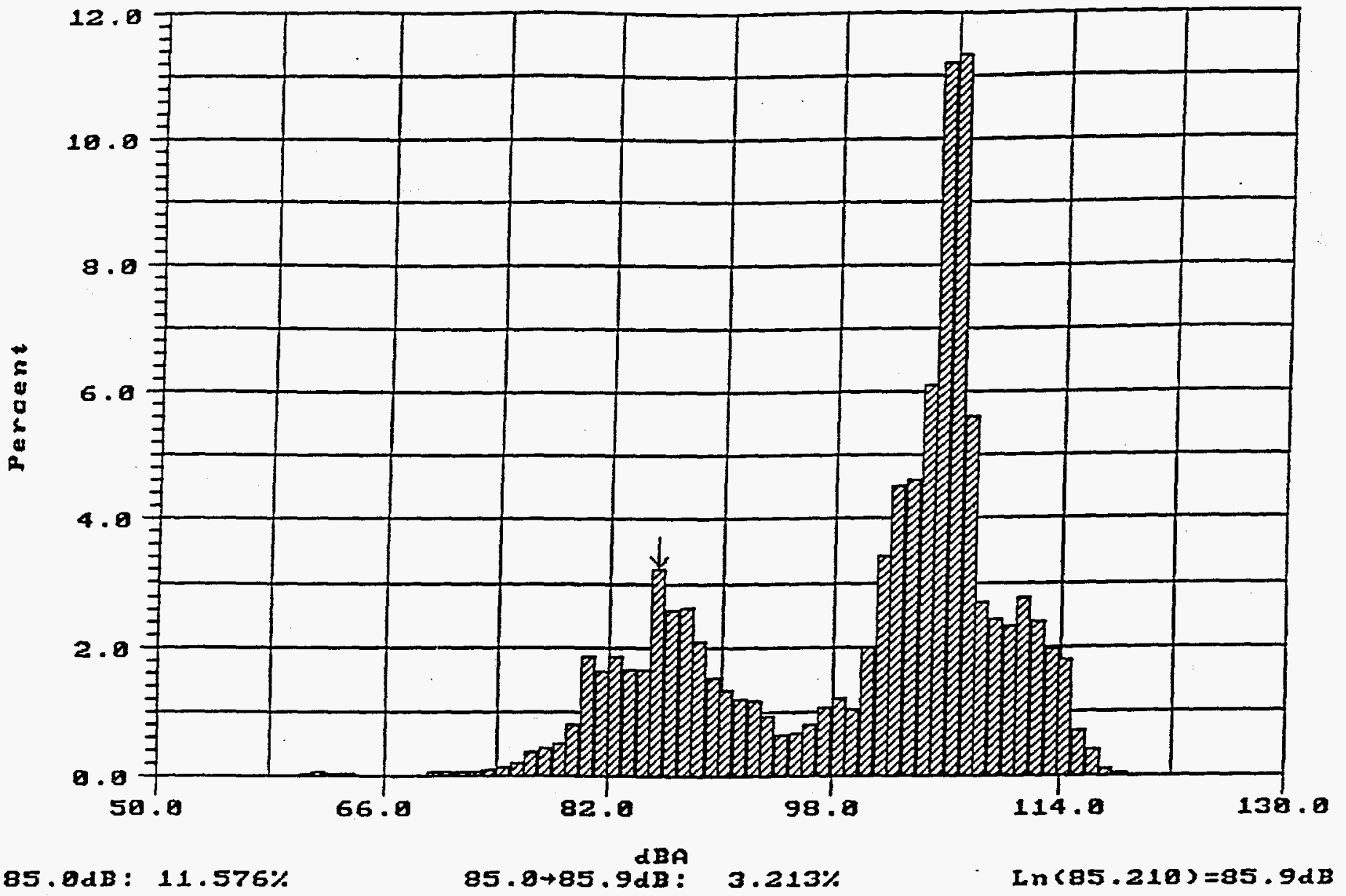

The percentage of time spent at each decibel level can be obtained from the graph. As shown, $11.576 \%$ of the time the noise exposure was less than $85 \mathrm{dBA}$ which means that the majority of the time or $88.424 \%$ of the time the noise exposure was at sound levels above $85 \mathrm{dBA}$. OSHA requires that a hearing conservation program be initiated if the 8-hour TWA is $85 \mathrm{dBA}$. 